\title{
Translation, adaptation, and initial validation of the Food Allergy Quality of Life Questionnaire - Parent Form (0-12 years) in Ukrainian language
}

\author{
Oksana Matsyura' ${ }^{1,2}$, Anna Menshykova', Lesya Besh'1, Taras Gutor ${ }^{3}$, Oksana Kovalska3, \\ Olesya Besh ${ }^{4}$, Olena Sorokopud ${ }^{4}$, Natalia Lukyanenko ${ }^{5}$, Bertine Flokstra-de Blok ${ }^{6,7}$ \\ 'Department of Pediatrics №2, Danylo Halytsky Lviv National Medical University, Lviv, Ukraine \\ ${ }^{2}$ Communal Nonprofit Enterprise "City Children's Clinical Hospital of Lviv", Allergy Department, Ukraine \\ ${ }^{3}$ Department of Social Medicine, Economics and Organization of Health Care, Danylo Halytsky Lviv National Medical \\ University, Lviv, Ukraine \\ ${ }^{4}$ Department of Internal Medicine №2, Danylo Halytsky Lviv National Medical University, Lviv, Ukraine \\ ${ }^{5}$ Department of Propaedeutic Pediatrics and Medical Genetics, Danylo Halytsky Lviv National Medical University, Lviv, Ukraine \\ ${ }^{6}$ General Practitioners Research Institute (GPRI), Groningen, the Netherlands \\ ${ }^{7}$ University of Groningen, University Medical Center Groningen, Beatrix Children's Hospital, Department of Pediatric \\ Pulmonology and Pediatric Allergology, Groningen, the Netherlands
}

\section{ABSTRACT}

Aim of the study: The objective of this study was aimed at the translation, adaption, and initial validation of the Food Allergy Quality of Life Questionnaire - Parent Form (FAQLQ-PF) (0-12 years) into Ukrainian language.

Material and methods: Sixty patients with cow's milk allergy and their parents were involved in the study. The FAQLQ-PF translated into Ukrainian language and the Ukrainian version of the Food Allergy Independent Measure (FAIM) were used. Forward and backward translations were done. One independent Ukrainian translator produced forward translations, and 2 other bilingual translators worked on the backward translation according to the World Health Organization guidelines. Construct validity of the Ukrainian FAQLQPF (U-FAQLQ-PF) was checked by calculating correlation coefficients between FAIM and U-FAQLQ-PF. The internal consistency was assessed using Cronbach's alpha coefficient and corrected item-total correlations. Confirmatory factor analysis was used to test the originally proposed 3-factor structure with our data.

Results: Feasibility of the U-FAQLQ-PF was $100 \%$, all questionnaires were fully completed by the parents. The total U-FAQLQ-PF scores correlated significantly with the total FAIM. The factor analysis resulted in 3 factors that confirmed the original ones. All the factors had strong loadings from 0.575 to 0.840 . Cronbach alphas were 0.72 for the total U-FAQLQ-PF and 0.76-0.84 for its subscales. Corrected item-total correlation was between 0.27 and 0.67 for the total U-FAQLQ-PF, but for each subscale it was $>0.300$. Cronbach `s alpha was not increased for the scale and subscales after deletion of any item.

Conclusions: The Food Allergy Quality of Life Questionnaire - Parent Form (0-12 years) in Ukrainian language has satisfactory validity and reliability and can be used to improve the management of children with food allergies and in clinical trials.

KEY WORDS:

children, questionnaire, validation, health-related quality of life.

\section{ADDRESS FOR CORRESPONDENCE:}

Oksana Matsyura, Department of Pediatrics №2, Danylo Halytsky Lviv National Medical University, 4 Pylyp Orlyk Str., Lviv 79058, Ukraine, e-mail: omatsyura@gmail.com 


\section{INTRODUCTION}

The incidence of food allergy has been increasing in recent last years $[1,2]$. Cow's milk protein is the main cause of food allergy in infants and children under 3 years old [2]. According to recent estimation, the incidence of cow's milk protein allergy (CMPA) varies from $2 \%$ to $3 \%$, but clinically it is suspected in up to $17 \%$ of infants $[3,4]$. Symptoms of CMPA usually occur within the first few months of life [5]. Manifestations mainly develop in the digestive tract, skin, and respiratory system. The severity of CMPA varies from mild-moderate to severe [4] and can affect patients' and their families' quality of life $[1,5]$.

Specific questionnaires, named the Food Allergy Quality of Life Questionnaires (FAQLQ), for children from 0 to 18 years have been developed and validated in Europe for assessing health-related quality of life (HRQoL) and establishing the burden of food allergy [6-9]. The FAQLQ-Parent Form (FAQLQ-PF), representing such a questionnaire, has excellent reliability and validity and may be useful in trails, for problems of identification in food-allergic children, assessment of clinical interventions effectiveness, and evaluation of outcomes $[6,7,10]$. The data obtained with this form may facilitate the treatment of children with CMPA.

A survey in the United Kingdom revealed that there can be a significant difference in perception of symptom presentation and improvement between the general practitioners and the parents of children with CMPA. Also, a significant burden on both families and general practitioners was identified [5]. The use of questionnaires can improve understanding and communication between physicians, patients, and their parents. That is why the FAQLQ is an important tool for improving management and should be a part of it. However, considering that HRQoL is a multifactorial construct and includes physical, psychological, and social components [11], these questionnaires should be translated and adapted, taking into account the cultural features and the socioeconomic situation of the country in which they are to be used $[12,13]$.

This study aims to translate, adapt, and perform initial validation of the FAQLQ-PF (0-12 years) in the Ukrainian language.

\section{MATERIAL AND METHODS}

\section{PATIENTS}

Sixty patients with objectively diagnosed allergy to cow's milk and their parents were involved in a survey. Informed consent form was obtained from the parents.

The inclusion criteria were age 6 months -3 years, positive prick test ( $\geq 3 \mathrm{~mm}$ ), level of serum CMP specific $\mathrm{IgE} \geq 0.35 \mathrm{kUa}$, and a positive oral tolerance test (OTT) with cow's milk. CMPA was confirmed by clinical symptoms and laboratory data (Table 1).

Patients with autoimmune diseases, as well as those who had contraindication to OTT (because of previous clinical symptoms of anaphylaxis), or if it was impossible to perform OTT, were excluded from the study. The OTT was performed on all patients included in the study. The children were healthy at the time of the OTT.

\section{OTT PROCEDURE}

An intravenous catheter was inserted before the OTT. The test was performed using fermented milk formula "NAN 2 OPTIPRO" (Nestle) with a protein content of $1.3 \mathrm{~g}$ per $100 \mathrm{ml}$. The dose was increased every 15-30 minutes. The algorithm included 8 steps. The starting dose was $0.013 \mathrm{~g}$ of protein. The maximum cumulative dose was $4.108 \mathrm{~g}$ of protein [14]. The patients were observed in the clinic

TABLE 1. Patients' epidemiological and clinical characteristics

\begin{tabular}{|l|c|}
\hline Characteristics & Patients $(n=60)$ \\
\hline Male & $39(65)$ \\
\hline Female & $21(35)$ \\
\hline Age, months & $20.73 \pm 7.01$ \\
\hline Duration of disease & $11[7-14.25]$ \\
\hline Cutaneous symptoms & $28(48.33)$ \\
\hline Gastrointestinal symptoms & $20(33.33)$ \\
\hline Respiratory symptoms & $4(6.67)$ \\
\hline Multisystemic symptoms & $7(11.67)$ \\
\hline Consume amount of formula during oral tolerance test, $\mathrm{ml}$ & $86.5[57.25-110.5]$ \\
\hline Consume cow's milk protein during oral tolerance test, $\mathrm{ml}$ & $1.12[0.74-1.44]$ \\
\hline Prick test reaction, mm ${ }^{2}$ & $4.94 \pm 1.17$ \\
\hline Serum level of lgE to cow's milk protein, kUa & $3.62[2.56-5.33]$ \\
\hline
\end{tabular}

Data are presented as number of cases (\%), mean \pm SD or median [min-max] 
Table 2. Spearman's correlation coefficients of the total Ukrainian-Food Allergy Quality of life Questionnaire-Parent Form (U-FAQLQ-PF) score and its domains and questions with the total Food Allergy Independent Measure (FAIM) score and its questions

\begin{tabular}{|l|c|c|c|c|c|}
\hline U-FAQLQ-PF & Q1 & Q2 & Q3 & Q4 & FAIM Total \\
\hline Total & $0.73^{*}$ & $0.67^{*}$ & $0.66^{*}$ & $0.57^{*}$ & $0.88^{*}$ \\
\hline \begin{tabular}{l} 
Emotional impact subscale \\
\hline 2 Different from other children
\end{tabular} & 0.25 & $0.26^{*}$ & $0.56^{*}$ & $0.68^{*}$ & $0.62^{*}$ \\
\hline 6 Experiences physical distress & $0.28^{*}$ & $0.33^{*}$ & $0.5^{*}$ & $0.56^{*}$ & $0.57^{*}$ \\
\hline 7 Experiences emotional distress & $0.33^{*}$ & $0.29^{*}$ & $0.48^{*}$ & $0.44^{*}$ & $0.51^{*}$ \\
\hline 9 Affected by more attention & 0.18 & 0.21 & $0.45^{*}$ & $0.41^{*}$ & $0.42^{*}$ \\
\hline 10 Grow up more quickly & 0.16 & $0.29^{*}$ & $0.38^{*}$ & $0.45^{*}$ & $0.45^{*}$ \\
\hline 11 Restricted environment & 0.2 & 0.13 & $0.42^{*}$ & $0.59^{*}$ & $0.48^{*}$ \\
\hline Food anxiety subscale & 0.15 & 0.05 & $0.43^{*}$ & $0.52^{*}$ & $0.41^{*}$ \\
\hline 1 Anxious about food & $0.75^{*}$ & $0.37^{*}$ & $0.43^{*}$ & $0.27^{*}$ & $0.56^{*}$ \\
\hline 4 Afraid to try unfamiliar foods & $0.60^{*}$ & $0.26^{*}$ & $0.28^{*}$ & 0.21 & $0.41^{*}$ \\
\hline 5 Reaction to food & $0.66^{*}$ & $0.33^{*}$ & $0.35^{*}$ & 0.21 & $0.48^{*}$ \\
\hline Social and dietary limitations subscale & $0.65^{*}$ & $0.34^{*}$ & $0.42^{*}$ & 0.25 & $0.51^{*}$ \\
\hline 3 Frustrated by dietary restrictions & $0.44^{*}$ & $0.64^{*}$ & 0.15 & -0.03 & $0.38^{*}$ \\
\hline 8 Lack of variety in diet & $0.29^{*}$ & $0.45^{*}$ & 0.002 & 0.01 & 0.25 \\
\hline 12 Limitations on restaurants & $0.28^{*}$ & $0.38^{*}$ & 0.07 & -0.11 & 0.18 \\
\hline 13 Limitations on holiday destinations & 0.25 & $0.48^{*}$ & -0.01 & -0.03 & 0.2 \\
\hline 14 Limited social activities & 0.25 & $0.43^{*}$ & 0.18 & -0.06 & $0.27^{*}$ \\
\hline
\end{tabular}

Notes. * correlation is significant $(p<0.05)$. Q1: What chance do you think your child has of accidentally ingesting the food to which they are allergic? Q2: What chance do you think your child has of having a severe reaction if food is accidentally ingested? Q3: What chance do you think your child has of dying from his/her food allergy following ingestion in the future? Q4: What chance do you think your child has of effectively treating him/herself, or receiving effective treatment from others (including Epipen administration), if he/she accidentally ingests a food to which he/she is allergic?

for 2 hours after the test. Parents were contacted by phone about their children's health 24 and 48 hours after the test.

\section{QUESTIONNAIRES}

We used 2 questionnaires: the FAQLQ-PF translated into Ukrainian language and the Ukrainian version of the Food Allergy Independent Measure (FAIM), which the parents had to complete.

The FAQLQ-PF for the age group of $0-3$ years has 14 items and 3 domains (emotional impact [EI], food anxiety [FA], and social and dietary restrictions [SR]). Each question of the FAQLQ-PF is answered on a 7-point scale.

The FAIM has 2 groups of questions, and it measures the perceived severity of food allergy [6]. We used only the first group of questions because of the children's age. Each question of the FAIM was answered on a 7-point scale (0-6) and recorded. Total FAIM scores were calculated by dividing the sum of completed items by the number of completed items.

All questionnaires were fully completed by the parents.

\section{TRANSLATION AND CULTURE ADAPTATION}

One independent Ukrainian translator produced forward translations, and 2 other bilingual translators performed backward translation according to the WHO guidelines. During this process 2 inadequate expressions were identified and changed. To ensure face validity, this version was given to 10 parents of 0 -3-year-old children with food allergies.

Parents did not have any difficulties with food allergy quality of life questions and food allergy independent measurement items.

\section{VALIDATION}

The construct validity of the FAQLQ-PF was checked by calculating the Spearman correlation coefficients between the FAQLQ-PF and the FAIM questionnaires.

Confirmatory factor analysis was implemented in order to test the originally proposed 3 -factor structure with our data.

The internal consistency of the instrument was assessed using Cronbach's alpha coefficient (the total scale alpha should be at least 0.70 to be acceptable, 0.80 - to be good, and 0.90 - to be excellent; and the subscale alphas should be greater than corresponding expected alphas calculated using the Spearman-Brown formula), and corrected item-total correlations (Pearson's $r$ for each subscale should be $>0.300$, otherwise the item should be removed from the questionnaire).

\section{ETHICS DISCLOSURE}

The study was approved by the Ethics Committee of Nonprofit Communal Enterprise "City Children's Clinical 
Table 3. Confirmatory factor analysis: loadings ( $>0.3$ ) in each of our three factors (F1 to F3) for each question

\begin{tabular}{|l|l|l|l|l|}
\hline Question & Factor 1 & Factor 2 & Factor 3 & Subscale \\
\hline 2 & 0.840 & & & Emotional impact \\
\hline 6 & 0.706 & & & Emotional impact \\
\hline 7 & 0.747 & & & Emotional impact \\
\hline 9 & 0.575 & & & Emotional impact \\
\hline 10 & 0.661 & & & Emotional impact \\
\hline 11 & 0.638 & & 0.829 & Food anxiety \\
\hline 1 & & & 0.773 & Food anxiety \\
\hline 4 & & & 0.776 & Food anxiety \\
\hline 5 & & 0.650 & & Social and dietary limitations \\
\hline 3 & & 0.722 & & Social and dietary limitations \\
\hline 8 & & 0.597 & & Social and dietary limitations \\
\hline 12 & & 0.583 & & Social and dietary limitations \\
\hline 13 & & 0.632 & & Social and dietary limitations \\
\hline 14 & & & & \\
\hline
\end{tabular}

Table 4. Cronbach's alpha and corrected item-total correlation for Ukrainian-Food Allergy Quality of life Questionnaire-Parent Form

\begin{tabular}{|l|c|c|c|}
\hline Scale/Subscale & Number of items & Cronbach's alpha & Corrected item-total correlation \\
\hline Total scale & 14 & 0.72 & $0.27-0.67$ \\
\hline El & 6 & 0.84 & $0.59-0.83$ \\
\hline FA & 3 & 0.83 & $0.74-0.78$ \\
\hline SR & 5 & 0.76 & $0.55-0.69$ \\
\hline First half (questions 1-7) & 7 & 0.8 & $0.1-0.84$ \\
\hline Second half (questions 8-14) & 7 & 0.68 & $0.25-0.64$ \\
\hline
\end{tabular}

El - emotional impact; $F A$ - food anxiety; SR - social and dietary restrictions

Hospital of Lviv" on 16 November 2018 (Act №6). Full written parental consent was obtained.

\section{RESULTS}

The feasibility of the Ukrainian FAQLQ-PF (U-FAQLQ-PF) was $100 \%$ because all questionnaires were fully completed by the parents.

The total and 2 subscale U-FAQLQ-PF scores correlated significantly with the total FAIM and with the 4 individual FAIM questions (Table 2).

The factor analysis resulted in 3 factors that confirmed the original ones. All the factors had strong loadings from 0.575 to 0.840 (EI, 0.575-0.840; FA, 0.773-0.829; SR, 0.583-0.722; Table 3).

Cronbach alphas were 0.72 for the total U-FAQLQ-PF and for its subscales from 0.76 to 0.84 . Corrected item-total correlation was between 0.27 and 0.67 for the total U-FAQLQ-PF, but for each subscale it was > 0.500 (Table 4).

Cronbach's alpha was not increased for the scale and subscales after deletion of any item. Two items had corrected item-total correlations less than 0.300 (item 4 and item 8 ), but for the subscales it was $>0.500$ for both items (Table 5).

\section{DISCUSSION}

Allergy to cow's milk protein is a considerable problem because dairy products are a valuable component of the diet of young children. Assessment of quality of life is an important part of the management of children suffering from food allergies $[12,15]$.

The risk of allergic reaction limits children in their autonomous activities. Children and their parents may be affected by health problems, elimination diets, the need to comply with certain restrictions and take precautions, as well as by the fear of potentially severe allergic reactions $[1,15]$. This can affect the behaviour of the whole family because of the restriction of social activities due to the food allergy [15]. In research it was revealed that children with food allergies had worse quality of life than children with chronic disease $[16,17]$. The FAQLQ-PF has been developed for younger children [6]. This questionnaire has been translated and validated in different countries. Investigations showed that the feasibility, reliability, and internal consistency were good for FAQLQ-PF in general and for its different subscales [6, 7, 10, 12, 13, 15]. Therefore, FAQLQ-PF is an optimal tool for estimating quality of life in food allergy patients. 
TABLE 5. Cronbach's alpha if item was deleted from subscale and corrected item-total correlation for items for subscales of Food Allergy Quality of life Questionnaire-Parent Form

\begin{tabular}{|c|c|c|c|c|c|c|c|}
\hline \multicolumn{2}{|c|}{ Scale/ Item } & $\begin{array}{l}\text { a if item was deleted } \\
\text { from the scale }\end{array}$ & $\begin{array}{l}\text { Corrected item-total } \\
\text { correlation for the scale }\end{array}$ & \multicolumn{2}{|c|}{$\begin{array}{l}\text { Subscale/ } \\
\text { Item }\end{array}$} & $\begin{array}{l}\text { a if item was deleted } \\
\text { from the subscale }\end{array}$ & $\begin{array}{l}\text { Corrected item- } \\
\text { total correlation for }\end{array}$ \\
\hline \multirow{14}{*}{ 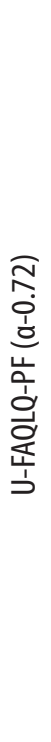 } & 2 & 0.67 & 0.67 & \multirow{6}{*}{ 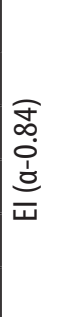 } & 2 & 0.79 & 0.83 \\
\hline & 6 & 0.68 & 0.63 & & 6 & 0.81 & 0.7 \\
\hline & 7 & 0.69 & 0.5 & & 7 & 0.81 & 0.73 \\
\hline & 9 & 0.69 & 0.53 & & 9 & 0.84 & 0.59 \\
\hline & 10 & 0.7 & 0.46 & & 10 & 0.83 & 0.64 \\
\hline & 11 & 0.7 & 0.43 & & 11 & 0.83 & 0.67 \\
\hline & 1 & 0.72 & 0.3 & \multirow{3}{*}{ 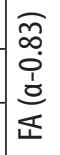 } & 1 & 0.75 & 0.78 \\
\hline & 4 & 0.72 & 0.27 & & 4 & 0.77 & 0.76 \\
\hline & 5 & 0.72 & 0.3 & & 5 & 0.77 & 0.74 \\
\hline & 3 & 0.71 & 0.36 & \multirow{5}{*}{ 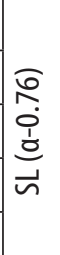 } & 3 & 0.71 & 0.69 \\
\hline & 8 & 0.72 & 0.28 & & 8 & 0.7 & 0.66 \\
\hline & 12 & 0.71 & 0.32 & & 12 & 0.73 & 0.63 \\
\hline & 13 & 0.71 & 0.41 & & 13 & 0.75 & 0.55 \\
\hline & 14 & 0.68 & 0.58 & & 14 & 0.71 & 0.63 \\
\hline
\end{tabular}

El - emotional impact; $F A$ - food anxiety; SR - social and dietary restrictions; $a$ - Cronbach's alpha

In our study all questionnaires were completed, and no comments, doubts, or suggestions were posed. The strong significant correlation $(r=0.88 ; p<0.05)$ between U-FAQLQ-PF and FAIM confirmed the construct validity. Cronbach's alpha coefficient was 0.73 for total U-FAQLQ-PF and $>0.8$ for 2 out of 3 subscales in our study, which means good internal consistency. These results correspond to those obtained in other studies [10, 15]. No alpha was greater if an item was deleted than it was without deletion. Therefore, there was no indication for removal of any item. Item-total Pearson's correlations showed that most of the items are well related $(r>0.300)$, except for items 4 and 8 ( $r=0.27$ and $r=0.28$, respectively). But these items had strong correlations in subscales (Table 4). Hence, there was no need to remove them. Confirmatory factor analysis resulted in 3 factors that confirmed the original ones (Table 3).

Determining the quality of life of patients with food allergy is an important mechanism for the estimation of management and treatment effectiveness. HRQL may be the only meaningful outcome measure available to estimate continuous burden of food allergy $[12,18]$. FAQLQ-PF can also be used in research to assess the impact of various interventions on patients' quality of life. Due to the significant negative impact of food allergy on quality of life, this questionnaire should be widely used in children with allergies. Therefore, it is important to validate and culturally adapt this questionnaire for possible wide application.

\section{CONCLUSIONS}

U-FAQLQ-PF has satisfactory validity and reliability and can be used for improving the management of the children with food allergies and in clinical trials.

\section{DISCLOSURE}

The authors declare no conflict of interest.

\section{REFERENCES}

1. Morou Z, Tatsioni A, Dimoliatis IDK, et al. Health-related quality of life in children with food allergy and their parents: a systematic review of the literature. Investig Allergol Clin Immunol 2014; 24 : 382-395.

2. Koletzko S, Niggemann B, Arato A, et al. Diagnostic approach and management of cow's-milk protein allergy in infants and children: ESPGHAN GI committee practical guidelines. JPGN 2012; 55 : 221-229.

3. Katz A, Hundal NV, Yuan Q, et al. Cow's milk allergy: a new approach needed? J Pediatrics 2013; 163: 620-622.

4. De Greef E, Hauser B, Devreker T, et al. Diagnosis and management of cow's milk protein allergy in infants. World J Pediatr 2012; 8: 19-24.

5. Lozinsky AC, Meyer R, Anagnostou K, et al. Cow's milk protein allergy from diagnosis to management: a very different journey for general practitioners and parents. Children 2015; 2: 317-329.

6. Dunn Galvin A, Flokstra-de Blok BMJ, Burks AW, et al. Food allergy Qol questionnaire for children aged 0-12 years: content, construct, and cross-cultaral validity. Clin Exp Allergy 2008; 38 : 977-986. 
7. Dunn Galvin A, Culliane C, Daly DA, et al. Longitudinal validity and responsiveness of the food allergy quality of life questionnaire parent form in children 0-12 years following positive and negative food challenges. Clin Exp Allergy 2010; 40: 476-485.

8. Flokstra-de Blok BMJ, Dunn Galvin A, Vlieg-Boerstra BJ, et al. Development and validation of a self-administered Food Allergy Quality of Life Questionnaire for children. Clin Exp Allergy 2009; 39: 127-137.

9. Flokstra-de Blok BMJ, Dunn Galvin A, Vlieg-Boerstra BJ, et al. Development and validation of a self-administered Food Allergy Quality of Life Questionnaire for adolescents. J Allergy Clin Immunol 2008; 122: 139-144.

10. Indinnimeo L, Baldini L, De Vittori V, et al. Duration of a cowmilk exclusion diet worsens parents' perception of quality of life in children with food allergies. BMC Pediatrics 2013; 13: 203.

11. Dunn Galvin A, Chang W, Laubach S, et al. Profiling families enrolled in food allergy immunotherapy studies. Pediatrics 2009; 124: 503-509.

12. Manso L, Pineda R, Huertas B, et al. Validation of the Spanish Version of the Food Allergy Quality of Life Questionnaire-Parent Form (S-FAQLQ-PF). J Investig Allergol Clin Immunol 2017; 27: 363-369.

13. Couto M, Silva D, Piedade S, et al. Translation to Portuguese and cultural adaptation of Food Allergy Quality of Life Questionnaire Parent Form (FAQLQ-PF). Eur Ann Allergy Clin Immunol 2016; 48: 82-87.

14. Besh L, Muraro A, Matsyura O, Bonaguro R. Experience in diagnostics and treatment of milk allergy in children in Padua (Italy). Asthma and Allergy 2017; 3: 64-71.

15. Wassenbera J, Cochard MM, DunnGalvin A, et al. Parent perceived quality of life is age-dependent in children with food allergy. Pediatr Allergy Immunol 2012; 23: 412-419.

16. Avery NJ, King RM, Knight S, et al. Assessment of quality of life in children with peanut allergy. Pediatr Allergy Immunol 2003; 14 : 378-382.

17. Primeau MN, Kagan R, Joseph L, et al. The psychological burden of peanut allergy as perceived by adults with peanut allergy and the parents of peanut-allergic children. Clin Exp Allergy 2000; 30: 1135-1143.

18. Antolin-Amerigo D, Manso L, Caminati M, et al. Quality of life in patients with food allergy. Clin Mol Allergy 2016; 14. DOI 10.1186/ s12948-016-0041-4. 